\title{
An exo- $\beta$-(1,3)-glucanase of Candida albicans: purification of the enzyme and molecular cloning of the gene
}

\author{
Ross S. Chambers, ${ }^{1}$ Michael J. Broughton, ${ }^{1}$ Richard D. Cannon, ${ }^{2}$ Alan Carne, ${ }^{1}$ \\ George W. Emerson ${ }^{1}$ and Patrick A. Sullivan ${ }^{1 *}$ \\ ${ }^{1}$ Biochemistry Department and ${ }^{2}$ Experimental Oral Biology Unit, University of Otago, PO Box 56, \\ Dunedin, New Zealand
}

(Received 24 July 1992; revised 20 October 1992; accepted 27 October 1992)

\begin{abstract}
A nucleotide sequence encoding an exo- $\beta$ - $(1,3)$-glucanase was cloned from a library of genomic DNA of Candida albicans ATCC 10261. The sequenced gene encodes a protein of 438 amino acid residues. The amino terminal and an internal peptide sequence of the enzyme matched with deduced sequences within the cloned gene. Analysis of the sequence indicated that the nascent protein is processed during secretion by the signal peptidase and a Kex2like proteinase, yielding a predicted mature enzyme of $\mathbf{4 0 0}$ residues. There is $58 \%$ identity and $85 \%$ similarity between the amino acid sequences of this exoglucanase and the homologous enzyme of Saccharomyces cerevisiae. An antiserum to the purified exoglucanase cross-reacted with the $S$. cerevisiae exoglucanase and a similar protein secreted by other $C$. albicans strains and $C$ andida species. There are no sites for $N$-linked glycosylation in the sequence and this is consistent with the carbohydrate content of the secreted enzyme. Putative upstream promoter elements are associated with the gene. Southern analysis of the gene indicated that it was present at one copy per genome and that the diploid genome of $C$. albicans ATCC 10261 is heterozygous at this locus for a BgIII RFLP. A $2.5 \mathrm{~kb}$ mRNA transcript was detected by Northern analysis and gene expression, as monitored by Northern and Western blots, reflected the growth rates of the cultures.
\end{abstract}

\section{Introduction}

Many yeasts and fungi secrete endo- and exo- $\beta$-glucan hydrolases ( $\beta$-glucanases) to the cell surface. In most instances the exact physiological roles of these enzymes are unknown (for reviews see Nombela et al., 1988; Fleet, 1991) but they undoubtedly participate in the metabolism of $\beta$-glucan, the main structural component of the cell wall. The most widely accepted role of glucanases is localized hydrolysis of $\beta$-glucan during morphogenic events. Exoglucanases have been detected in many yeasts but not Schizosaccharomyces pombe (Fleet, 1991). The most abundant exo-enzyme of vegetative cells of Saccharomyces cerevisiae is secreted in two forms; I, with $M_{\mathrm{r}} 83000$ containing $40 \%$ carbohydrate and the more abundant II, $M_{\mathrm{r}} 56000$ with a carbohydrate content of $11 \%$ (Ramirez et al., 1990). Both isoforms exhibit the same catalytic specificity for $\beta$ -

\footnotetext{
*Author for correspondence. Tel. +643479 7863; fax +643479 7866
}

The sequence data reported in this paper have been submitted to EMBL and have been assigned the accession number X56556
1,3 bonds and also hydrolyse $p$-nitrophenol- $\beta$-glucoside and other glycosidic linkages at lower rates. Another exoglucanase is specifically produced by $S$. cerevisiae during meiosis (del Rey et al., 1982) and there is evidence for a third exo-enzyme (Cenamor et al., 1987; Hien \& Fleet, 1983; Vasquez de Aldana et al., 1991).

Recently, the gene for the abundant vegetative exoglucanase of $S$. cerevisiae EXG1 was cloned and sequenced (Vasquez de Aldana et al., 1991). The open reading frame codes for a protein of 448 amino acids which includes a leader sequence preceding the amino terminus of the mature enzyme.

Only one exoglucanase has been detected in Candida albicans, and it accounts for most of the total glucanase activity (production of reducing sugar from the soluble $\beta-1,3$ polymer laminaran) in the growth medium and cell extracts (Molina et al., 1987; Ram et al., 1988; LunaArias et al., 1991). One preparation of the enzyme purified from cell extracts contained two polypeptides and it was concluded that the enzyme was a heterodimer of subunits $M_{\mathrm{r}} 63000$ and 44000 (Molina et al., 1989). More recently, the enzyme isolated from the growth medium was shown to be monomeric with $M_{\mathrm{r}} 38000$ (Luna-Arias et al., 1991). 
In this paper we describe the purification of the exoglucanase from the growth medium of $C$. albicans ATCC 10261, the cloning and sequencing of the gene encoding the enzyme, and studies on the gene expression.

\section{Methods}

Organisms and plasmids. Unless otherwise stated, C. albicans strain ATCC 10261 was used throughout this work. Escherichia coli strains DH5 $\alpha$ and TG1 were hosts for recombinant plasmids and bacteriophage M13 respectively. E. coli strains NM538 and NM539 were hosts for bacteriophage $\lambda$. The plasmid pUC9 was used for subcloning experiments, and bacteriophages $\mathrm{M} 13 \mathrm{mp} 10$ and $\mathrm{M} 13 \mathrm{mp} 19$ were used to generate single-stranded templates for sequencing. A library of genomic DNA from $C$. albicans ATCC 10261 was in the bacteriophage גEMBL4. Genotypes of $E$. coli strains and details of the bacteriophages and plasmids used in this study are listed elsewhere (Brown, 1991). Candida tropicalis CDC B397, Candida kefyr CDC B2455 and Candida parapsilosis CDC MCC 499 were from the Center for Disease Control Collection, Atlanta, USA. Saccharomyces cerevisiae X2180-1a was obtained from the Yeast Genetic Stock Center, Berkeley, USA. Trichosporon cutaneum ATCC 20509 was from the American Type Culture Collection, Rockville, USA. Candida albicans SA280 was obtained from Dr A. Cassone, Istituto Superiore di Sanita, Rome, Italy and Candida albicans 3153a was obtained from Dr D. Howard, Department of Microbiology and Immunology, University of California, Los Angeles, USA.

Media and reagents. Yeast cultures were usually grown in a YPD medium containing $1 \%(\mathrm{w} / \mathrm{v})$ yeast extract, $2 \%(\mathrm{w} / \mathrm{v})$ peptone and $2 \%(\mathrm{w} / \mathrm{v})$ glucose. $E$. coli cultures were grown in Luria broth, supplemented with ampicillin as required, and strains carrying M13 were grown in $2 \times$ YT broth (Sambrook et al., 1989). DNA polymerase I (Klenow fragment), T4 polynucleotide kinase, $\left[\alpha-{ }^{32} \mathrm{P}\right] \mathrm{dATP},[\alpha-$ ${ }^{35}$ S $]$ dATP, $\left[\gamma_{-}{ }^{32} \mathrm{P}\right] \mathrm{dATP}$, Hybond-C and Hybond- $\mathrm{N}^{+}$were from Amersham International. Taq DNA polymerase was from Perkin Elmer Cetus, T4 DNA ligase was from Promega and restriction endonucleases were from Boehringer Mannheim. T4 DNA polymerase was from New England Biolabs. Zymolyase 100T and endoglycosidase $\mathrm{H}$ were obtained from Seikagaku Kogo, and horseradish-peroxidaselinked goat anti-rabbit antibody was from Caltag Laboratories. Oligonucleotides were produced by an Applied Biosystems 380B synthesizer using $\beta$-cyanoethyl chemistry. All other reagents were from Sigma.

Growth conditions Liquid yeast cultures were grown at $30^{\circ} \mathrm{C}$ on a gyrotary shaker (200 r.p.m.) and growth was measured as $\mathrm{OD}_{600}$ with a LKB Novospec II spectrophotometer.

Enzyme purification. Exoglucanase was purified from 101 cultures grown in a New Brunswick Microgen fermenter in a medium containing $0.5 \%$ yeast extract, $1 \%(\mathrm{w} / \mathrm{v})$ casein acid hydrolysate and $2 \%(\mathrm{w} / \mathrm{v})$ glucose. Fermenter cultures were inoculated with $200 \mathrm{ml}$ of a $24 \mathrm{~h}$ culture grown in the same medium and subsequently grown for $40 \mathrm{~h}$ at $30^{\circ} \mathrm{C}$ with $101 \mathrm{~min}^{-1}$ aeration and 400 r.p.m. agitation. The cells were harvested in a continuous flow centrifuge and the medium was concentrated to approximately $500 \mathrm{ml}$ by ultrafiltration $\left(M_{\mathrm{r}} 10000\right.$ cut-off filter). The concentrate was dialysed against $10 \mathrm{~mm}$-sodium acetate buffer, $\mathrm{pH} 5 \cdot 6$, and treated batchwise with DEAE-cellulose (Waitaki International) equilibrated in the same buffer $(0.4$ bed $\mathrm{vol} / \mathrm{vol})$. The unbound material containing the exoglucanase was collected by filtration, $\mathrm{NaCl}$ was added to $1 \mathrm{M}$ and the solution was mixed with phenyl sepharose (Pharmacia) ( $0 \cdot 1$ bed vol/vol) equilibrated in the same buffer. The phenyl sepharose was collected by filtration and washed on the filter with the same buffer. The bound enzyme was eluted with $50 \%(\mathrm{v} / \mathrm{v})$ acetonitrile, dialysed against $0 \cdot 1 \mathrm{M}$ sodium phosphate buffer, $\mathrm{pH} 7.0$ and concentrated by ultrafiltration to approximately $5 \mathrm{ml}$. Finally the enzyme was applied to a $60 \mathrm{~cm} \times 2 \cdot 15 \mathrm{~cm}$ gel filtration column (TSK G3000 SWG, Toyo Soda) equilibrated in the same buffer. The column was eluted at $2.5 \mathrm{ml} \mathrm{min}^{-1}$, the fractions $(2.5 \mathrm{ml})$ containing the enzyme were pooled, concentrated to approximately $5 \mathrm{ml}$ and stored at $4{ }^{\circ} \mathrm{C}$.

Determination of enzyme activity. Exoglucanase activity was determined with laminaran, $2 \mathrm{mg} \mathrm{ml}^{-1}$, in $80 \mathrm{~mm}$-sodium acetate buffer, pH 5.6. Assays $(250 \mu \mathrm{l})$ were incubated for $30 \mathrm{~min}$ at $37^{\circ} \mathrm{C}$ and the reactions were stopped by heating to $100^{\circ} \mathrm{C}$ for $10 \mathrm{~min}$. Glucose formation was measured by the glucose oxidase method (Bruss \& Black, 1978) and one unit of enzyme activity produced $1 \mu \mathrm{mol}$ glucose from laminaran per min. Alternatively, exoglucanase activity was determined by measuring the hydrolysis of $p$-nitrophenyl- $\beta$-glucoside. Each $250 \mu \mathrm{l}$ assay, containing $24 \mathrm{~mm}$-glucoside and $80 \mathrm{~mm}$-sodium acetate buffer, $\mathrm{pH} 5 \cdot 6$, was incubated for $30 \mathrm{~min}$ at $37^{\circ} \mathrm{C}$. The reactions were stopped by the addition of $80 \mu \mathrm{Na}_{2} \mathrm{CO}_{3}$ to a final concentration of $300 \mathrm{mM}$ and the $A_{414}$ was measured. One unit of activity catalysed the formation of $1 \mu \mathrm{mol} p$-nitrophenol per min.

Protein estimations. Protein was estimated by a modified Lowry method (Peterson, 1977) using bovine serum albumin as a standard.

Preparation of antiserum. Purified exoglucanase $(180 \mu \mathrm{g})$ was emulsified in Freund's complete adjuvant and injected subcutaneously into a New Zealand white rabbit. Additional exoglucanase, $90 \mu \mathrm{g}$ and $100 \mu \mathrm{g}$, was injected on days 22 and 36 respectively. Thirteen days after the last injection the rabbit was killed, the blood was allowed to clot and the antiserum was stored at $-20^{\circ} \mathrm{C}$.

Gel electrophoresis. SDS-PAGE was carried out with $10 \%(\mathrm{w} / \mathrm{v})$ acrylamide gels (Laemmli \& Favre, 1973) and the following proteins were used as molecular mass standards: bovine serum albumin $\left(M_{\mathrm{r}}\right.$ $66000)$, ovalbumin $\left(M_{\mathrm{r}} 45000\right)$, secreted aspartate proteinase of $C$. albicans $\left(M_{\mathrm{r}} 42000\right)$ and carbonic anhydrase $\left(M_{\mathrm{r}} 29000\right)$. Nondenaturing gels contained $10 \%(\mathrm{w} / \mathrm{v})$ acrylamide, with a continuous buffer system (Davis, 1964). Exoglucanase activity was examined by incubating the gels in $0.1 \mathrm{~m}$-sodium acetate, $\mathrm{pH} 5 \cdot 6$, containing $5 \mathrm{mg}$ laminarin $\mathrm{ml}^{-1}$ for $1 \mathrm{~h}$ and an activity stain which detected reducing sugars (Gabriel \& Wang, 1969).

Western blot analysis. Exoglucanase in samples of growth media $(800 \mu \mathrm{l})$ was precipitated with $50 \mu \mathrm{g}$ carrier BSA and trichloroacetic acid added to $8 \%(\mathrm{w} / \mathrm{v})$. The pellets were washed twice with ethanol and dissolved in $20 \mu \mathrm{l}$ loading buffer, separated by SDS-PAGE (see above) and electroblotted onto a nitrocellulose membrane using a carbonate buffer system (Dunn, 1986). Molecular mass standards were stained with $0.3 \%$ Ponceau $S$ and the remaining protein-binding sites on the membrane were blocked with buffered gelatine $[1 \%(\mathrm{w} / \mathrm{v})$ gelatine, $0.05 \%$ Tween 20, $8 \mathrm{~mm}-\mathrm{Na}_{2} \mathrm{HPO}_{4}, 1.5 \mathrm{~mm}-\mathrm{KH}_{2} \mathrm{PO}_{4}, 2.7 \mathrm{~mm}-$ $\mathrm{KCl}$ and $14 \mathrm{mM}-\mathrm{NaCl}$ ). Each membrane was incubated for $2 \mathrm{~h}$ with the rabbit anti-exoglucanase antiserum diluted 1:5000 in buffered gelatine. After three $10 \mathrm{~min}$ washes in the buffered gelatine the membrane was incubated for $2 \mathrm{~h}$ with a horseradish-peroxidase-linked goat anti-rabbit antibody diluted 1:5000 in the buffered gelatine. Following three $10 \mathrm{~min}$ washes in the buffered gelatine and one $5 \mathrm{~min}$ wash in $50 \mathrm{mM}$ Tris/ $\mathrm{HCl}, \mathrm{pH} \mathrm{8.0,} \mathrm{the} \mathrm{membrane} \mathrm{was} \mathrm{incubated} \mathrm{in} \mathrm{developing} \mathrm{solution}$ ( $0.05 \%$ diaminobenzidine, $0.01 \% \mathrm{H}_{2} \mathrm{O}_{2}$ in $50 \mathrm{~mm}$-Tris/ $\mathrm{HCl}, \mathrm{pH} 8.0$ ).

Carbohydrate analysis. For deglycosylation (Trimble \& Maley, 1984) each reaction contained $100 \mathrm{ng}$ pure exoglucanase in $100 \mathrm{~mm}$-sodium citrate buffer, $\mathrm{pH} 5.5$ with $12 \mathrm{mU}$ endoglycosidase $\mathrm{H}, 0.01 \%$ SDS, 0.5 mg BSA and $0.25 \mathrm{~mm}-\mathrm{PMSF}$ in a final volume of $100 \mu$ l. Detection of carbohydrate with concanavalin A involved electroblotting as described above, incubation with buffered gelatine, one wash with PCM buffer, pH 6.8 (20 mm-sodium phosphate, $0.1 \mathrm{~mm}-\mathrm{CaCl}_{2}, 0.1 \mathrm{~mm}-\mathrm{MnCl}_{2}$ ) and 
Table 1. Purification of the exoglucanase

\begin{tabular}{lccccc}
\hline \multicolumn{1}{c}{$\begin{array}{c}\text { Purification } \\
\text { step }\end{array}$} & $\begin{array}{c}\text { Total } \\
\text { activity } \\
(\mathrm{U})\end{array}$ & $\begin{array}{c}\text { Total } \\
\text { protein } \\
(\mathrm{mg})\end{array}$ & $\begin{array}{c}\text { Specific } \\
\text { activity } \\
\left(\mathrm{U} \mathrm{mg} \mathrm{m}^{-1}\right)\end{array}$ & $\begin{array}{c}\text { Yield } \\
(\%)\end{array}$ & $\begin{array}{c}\text { Purification } \\
\text { (-fold) }\end{array}$ \\
\hline Culture medium & 930 & 19000 & 0.05 & 100 & 1 \\
Concentrate & 870 & 2300 & 0.4 & 86 & 8 \\
DEAE-cellulose & 690 & 1800 & $0 \cdot 4$ & 74 & 8 \\
Phenyl-sepharose & 320 & 19 & 16.8 & 35 & 336 \\
Gel filtration & 120 & 1.8 & 67 & 13 & 1333 \\
\hline \hline
\end{tabular}

incubation with concanavalin A in PCM buffer $\left(5 \mu \mathrm{g} \mathrm{ml}^{-1}\right)$ for $2 \mathrm{~h}$ with and without $0.2 \mathrm{M}-\alpha$-methyl mannose. After four $5 \mathrm{~min}$ washes in buffered gelatine and one 5 min wash in PCM buffer, the membranes were incubated with horseradish peroxidase $\left(5 \mu \mathrm{g} \mathrm{ml}^{-1}\right)$ in PCM buffer for $2 \mathrm{~h}$. The membranes were washed as above and once in $20 \mathrm{~mm}-$ sodium phosphate, $\mathrm{pH} 6.8$, before incubation with developing solution as described above.

DNA manipulations. Restriction endonucleases and DNA modifying enzymes were used under the conditions recommended by the suppliers. Standard conditions for molecular cloning, hybridization, transformation and electrophoresis were used (Sambrook et al., 1989). Molecular mass markers for agarose gels were produced by digestion of bacteriophage $\lambda$ with HindIII and EcoRI. Yeast genomic DNA was isolated as described by Cryer $e$ t al. (1975). The basic protocol for PCR was as provided by Perkin Elmer Cetus. The sequence of the oligonucleotide primers used in PCR were: $C A(T / C) A A(T / C) G T(A /-$ G/C/T)GC(A/G/C/T)TGGGA(T/C)TA(T/C)AA and GTCATGTA(T/A)GGTTC(T/C)AAGACGAACCA. Each reaction $(20 \mu \mathrm{l})$ was for 40 cycles with a second portion of Taq DNA polymerase added at cycle 20. Optimized conditions included an annealing temperature of $48{ }^{\circ} \mathrm{C}$ and $3.5 \mathrm{~mm}-\mathrm{MgCl}_{2}$. DNA fragments of interest were recovered from agarose using DEAE paper (BioRad). DNA fragments were labelled with $\left[\alpha-{ }^{32} \mathrm{P}\right] \mathrm{dATP}$ as described by Feinberg \& Vogelstein (1984). A library of genomic DNA, prepared from $C$. albicans ATCC 10261 , was constructed in the cloning vector $\lambda E M B L 4$ (R. D. Cannon, unpublished results). The library screening and the purification of phage from positive plaques were as described by Ausubel et al. (1987). Phage DNA was purified from liquid lysates as described by Grossberger, (1987). A library of sub-fragments in M13 was generated by sonication (Bankier et al., 1987). DNA sequencing was performed by the dideoxynucleotide chain termination method with $\left[\alpha{ }^{35}\right.$ S $] \mathrm{dATP}$, a multiwell sequencing kit (Amersham) and the universal M13 forward primer. Yeast total RNA was isolated as described by Schmitt $e t$ al. (1990).

Computer programs. Editing, analysis and alignment of sequences was carried out using the programs VTUTIN, FASTA, CODONUSE, ALIGN, and HOMED (Pearson \& Lipman, 1988; Stockwell, 1985; Stockwell \& Petersen, 1987; Staden \& McLachlan, 1982).

\section{Results}

\section{Purification}

Table 1 summarizes a typical purification of the exoglucanase from the culture filtrate. Following concentration by ultrafiltration, a batchwise treatment with DEAE-cellulose was used to remove coloured impurities but this step did not increase the specific activity.

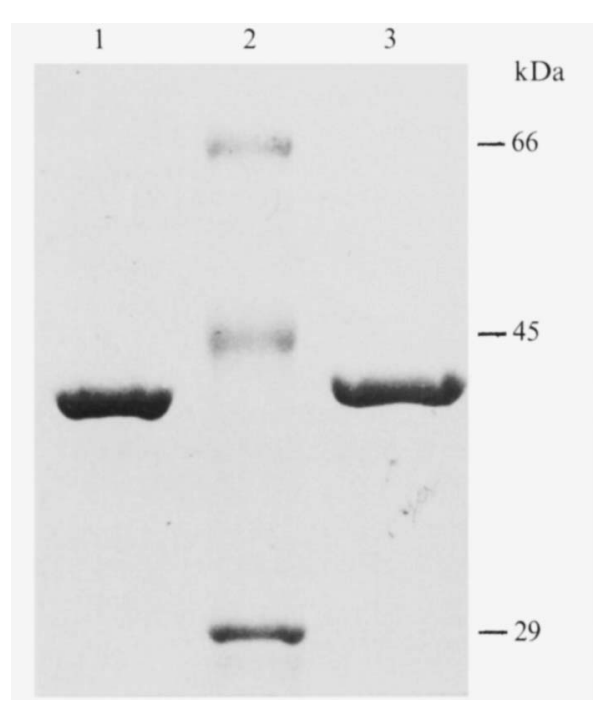

Fig. 1. SDS-PAGE of exoglucanase. A Coomassie-Blue-stained gel of 1 , purified exoglucanase $(5 \mu \mathrm{g}) ; 2$, bovine serum albumin, ovalbumin and carbonic anhydrase and 3 , purified secreted aspartate proteinase of C. albicans $(5 \mu \mathrm{g})$.

Preliminary experiments showed that the enzyme was tightly bound to phenyl sepharose and could be eluted with a high concentration of acetonitrile. This was exploited in a batchwise purification step which gave a 45-fold purification. Gel filtration chromatography yielded a preparation which exhibited one band with a $M_{\mathrm{r}}$ of 42000 in SDS-PAGE (Fig. 1). This is similar to the $M_{\mathrm{r}}$ of 38000 reported by Luna-Arias et al. (1991) for enzyme preparations from $C$. albicans strains $3153 \mathrm{a}$ and 1001. The specific activity of the purified enzyme $\left(65 \mathrm{U} \mathrm{mg}^{-1}\right.$ with laminaran and $2 \cdot 13 \mathrm{U} \mathrm{mg}^{-1}$ with $\mathrm{pNPG}$ ) is approximately twice that reported for a purified preparation from C. albicans 1001 (Molina et al., 1989). This can be accounted for by protein composition. The enzyme prepared from cell extracts of strain 1001 contained two bands $\left(M_{\mathrm{r}} 63000\right.$ and 44000$)$ in a $1: 1$ stoichiometry and it was concluded that the native enzyme was a heterodimer. Native gel electrophoresis of the enzyme prepared in the present work showed that it contained one band of protein coincident with the band 


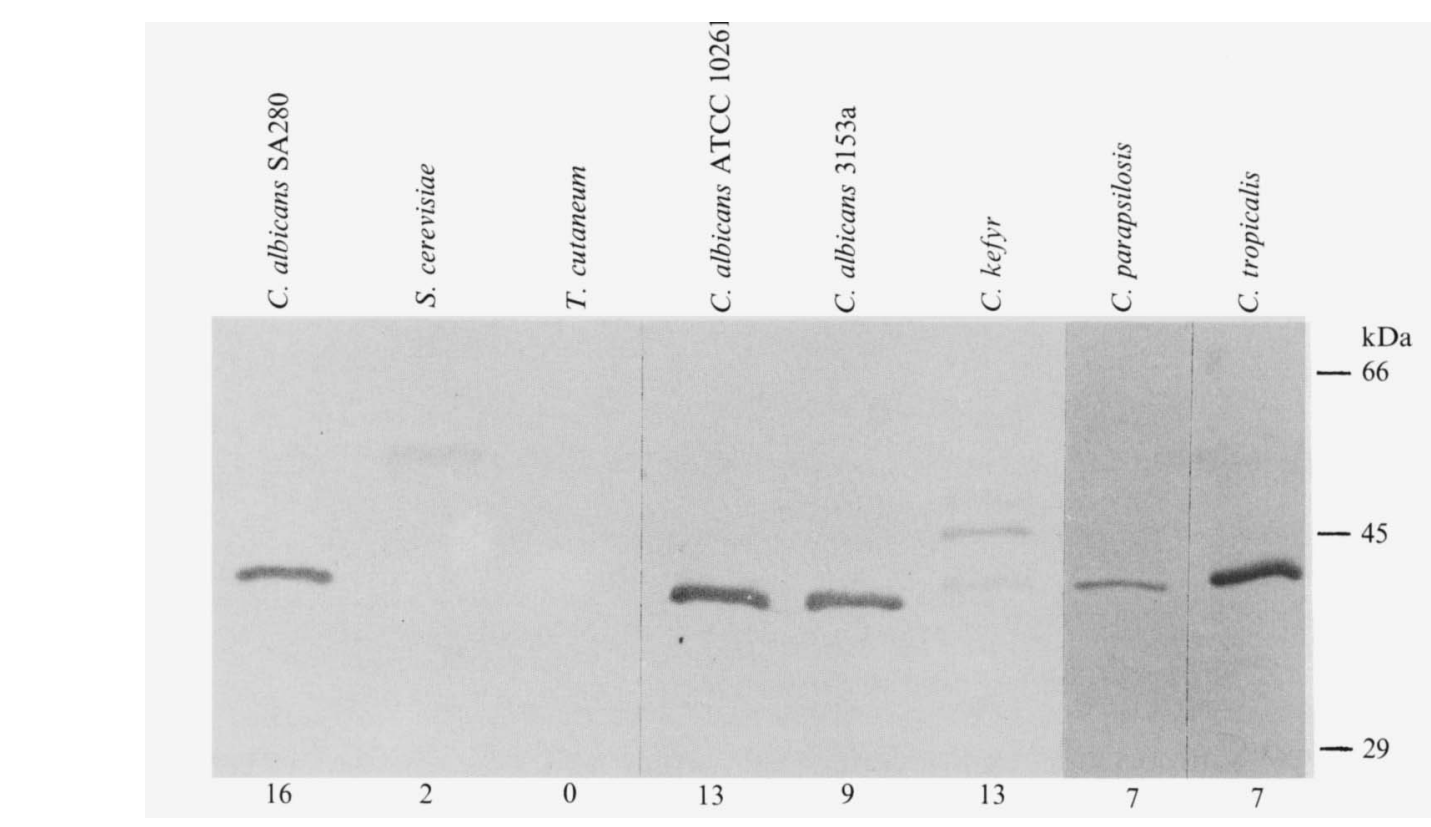

Fig. 2. Exoglucanase secretion by $C$. albicans strains and other yeasts. YPD cultures were incubated for $48 \mathrm{~h}$ at $30^{\circ} \mathrm{C}$ (entering stationary phase, $\mathrm{OD}_{600}=30$, after $20 \mathrm{~h}$ ) and $0.8 \mathrm{ml}$ samples of the culture media were analysed in a Western blot with the exoglucanase antiserum (see Methods). Exoglucanase activity in the culture media was measured with laminaran and is shown with each lane in milliunits $\mathrm{ml}^{-1}$.

of enzyme activity (data not shown). Analysis of the excised band by SDS-PAGE revealed only one protein of $M_{\mathrm{r}} 42000$. The present study and the recent report by Luna-Arias et al. (1991) indicate that the secreted enzyme is monomeric. Edman degradation of the intact enzyme yielded 35 residues of the amino acid sequence and confirmed that the preparation consisted of one polypeptide. This sequence was subsequently confirmed when the gene was cloned and sequenced (see below). Endoglycosidase $\mathbf{H}$ digestion, binding to concanavalin $\mathrm{A}$, and expression in the presence of tunicamycin, all indicated that the exoglucanase from $C$. albicans ATCC 10261 does not contain $N$-linked carbohydrate, and this is consistent with the analysis of the enzyme from strains 3153a and 1001 (Luna-Arias et al., 1991).

\section{Immunoreactivity}

Fig. 2 shows a Western blot analysis of concentrates of the growth media from cultures of several $C$. albicans strains, Candida species and two other yeasts. Each $C$. albicans sample contained only one immunoreactive band of $M_{\mathrm{r}} 42000$. Immunoreactive bands were detected in the culture medium of $C$. parapsilosis $\left(M_{\mathrm{r}} 43000\right), C$. tropicalis $\left(M_{\mathrm{r}} 44000\right)$ and $C$. kefyr $\left(M_{\mathrm{r}} 43000,47000\right.$, $52000,60000)$. The bands detected in the growth media of other Candida species probably represent exoglucanases secreted by these organisms. The multiple bands in the $C$. kefyr medium may represent several related gene products or heterogeneity arising from posttranslational modification of one gene product. The $M_{\mathrm{r}}$ 56000 band in the $S$. cerevisiae sample is as expected for the major glycosylated form of the exoglucanase secreted by this species (Ramirez et al., 1990). No bands were detected in the growth medium of $T$. cutaneum, but this is a more distantly related yeast with a different wall composition (J. Depree, personal communication).

\section{Cloning and sequencing of the exoglucanase gene}

Oligonucleotide primers (see Methods) for PCR were synthesised to deduced sequences of the $\mathrm{N}$-terminal protein sequence. One primer, a $23 \mathrm{mer}$, was based on the backtranslated sequence of residues 4-11 (HNVAWDYN). The second, a 26mer, was based on the template strand for residues 22-31 (WFVLEPYMT). PCR with genomic DNA from $C$. albicans ATCC 10261 as a template gave the expected band of $83 \mathrm{bp}$. This product was gel-purified, end-filled using DNA polymerase I (Klenow fragment) and T4 DNA polymerase, phosphorylated using T4 polynucleotide kinase, and ligated into the SmaI site of M13mp10. Sequencing four of the resultant clones confirmed that the PCR product encoded the expected region of the exoglucanase gene. The ${ }^{32} \mathrm{P}$ labelled $83 \mathrm{bp}$ fragment was used to probe a $\lambda$ EMBL4 library of $C$. albicans ATCC 
(a)
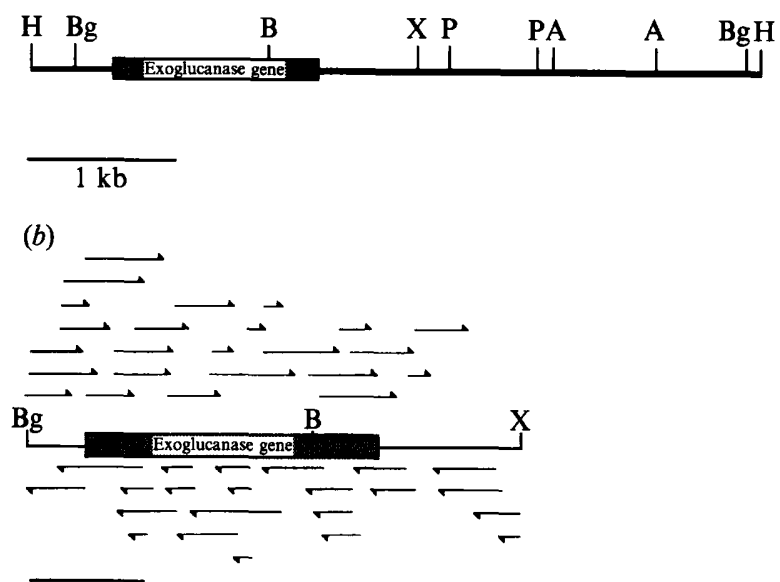

$0.5 \mathrm{~kb}$

Fig. 3. (a) Restriction map of the insert of pXG29. H, HindIII; B, BamHI, Bg, BglII; X, XbaI ; P, PstI; and A, AvaI. The following restriction endonucleases did not cut; SmaI, SacI, EcoRI, EcoRV and $K p n I$. (b) Sequencing strategy for the exoglucanase gene. Arrows indicate the directions and the extent of the DNA sequenced in various fragments of the random library generated from the $2.3 \mathrm{~kb} B g / \mathrm{II}-\mathrm{XbaI}$ fragment of pXG29. The sequences were compiled into a contiguous sequence using the program VTUTIN. Restriction sites of endonucleases used in mapping and the position of the ORF (box) are indicated.

10261 genomic DNA. A positive plaque was purified to homogeneity by repeated plating and probing with the $83 \mathrm{bp}$ probe. Digestion of the phage DNA with various restriction enzymes followed by Southern blots with the $83 \mathrm{bp}$ probe showed that the gene was contained on a $4.9 \mathrm{~kb}$ HindIII fragment. This was subsequently cloned into pUC9 giving rise to pXG29. Further analysis of pXG29 with restriction enzymes and Southern blots with the 83 bp probe localized the gene to a $2 \cdot 3 \mathrm{~kb} B g I I I-X b a I$ fragment (Fig. $3 a$ ) and this was used to construct a random sonicated sequencing library in M13mp10. Templates of clones prepared from the library were sequenced until the coding region of the gene, all of the cloned upstream region, $227 \mathrm{bp}$, and $156 \mathrm{bp}$ downstream of the termination codon was determined in both strands (Fig. 3b). As shown in Fig. 3(b), additional sequence in one strand (unpublished) was obtained in the downstream region. Southern analysis was used to determine the copy number and to detect any closely homologous genes in the genome. Genomic DNA from $C$. albicans ATCC 10261 digested with HindIII, PstI, EcoRI, BamHI and $B g l \mathrm{II}$ was probed with the $4.5 \mathrm{~kb} B g / \mathrm{II}$ fragment (Fig. $3 a$ ) and washed at medium stringency $\left(50^{\circ} \mathrm{C}, 0 \cdot 2 \times\right.$ SSC, $0.5 \%$ SDS). The number and the sizes of the bands (Fig. 4) were as expected except for the $B g I I$ digest. This restriction endonuclease yielded the expected $4.5 \mathrm{~kb}$ band and, additionally, bands at $1.9 \mathrm{~kb}$ and $2.6 \mathrm{~kb}$. At high stringency $\left(74^{\circ} \mathrm{C}, 0.2 \times \mathrm{SSC}, 0.5 \%\right.$ SDS) the probe bound to all the bands in the various digests including
$\begin{array}{lllll}B g & B & \text { E } & P & \text { H }\end{array}$

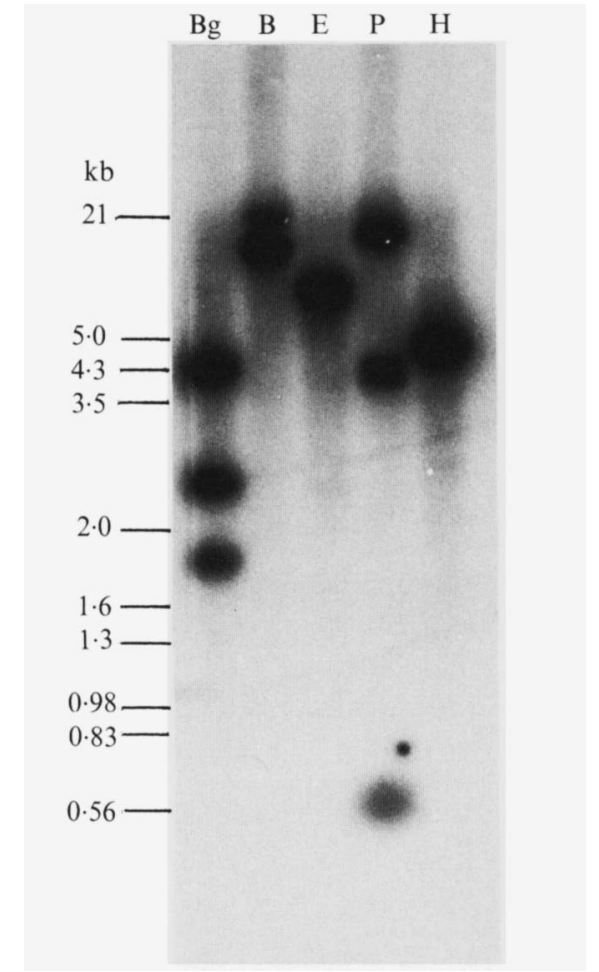

Fig. 4. Southern blot analysis. Genomic DNA from C. albicans ATCC 10261 was digested with various restriction endonucleases and analysed on a Southern blot using the $4.5 \mathrm{~kb} B g I I I$ fragment of pXG29 (see Methods). Stringency conditions used were $50^{\circ} \mathrm{C}$ with $0.2 \times$ SSC, $0.5 \%$ SDS. Bg, BgIII; B, BamHI; E, EcoRI; P, PstI; and H, HindIII.

the $2.6 \mathrm{~kb}$ and the $1.9 \mathrm{~kb}$ bands (data not shown). One possible explanation for this result is that in the C. albicans ATCC 10261 genome one of the two chromosomal homologues contains an additional $B g I I I$ restriction site, thus giving rise to a $B g / I I$ RFLP. Alternatively there could be a homologous gene present in the genome. The former alternative is more probable because; (i) no additional bands were detected in the HindIII, PstI, EcoRI and BamHI digests, (ii) all the bands bound to the probe at high stringency, (iii) the $1.9 \mathrm{~kb}$ and $2.6 \mathrm{~kb}$ bands added together equal the $4.5 \mathrm{~kb}$ band, and (iv) the single strand sequence data (unpublished) revealed a sequence one base different from a $B g I I I$ site and this is $1.9 \mathrm{~kb}$ from the upstream BglII site (see Fig. 5).

\section{Analysis of the sequence}

Analysis of the sequence revealed that the $2 \cdot 3 \mathrm{~kb} B g / \mathrm{II}-$ $X b a \mathrm{I}$ fragment contained an ORF of $1317 \mathrm{bp}$ coding for a protein of 438 residues with a predicted $M_{\mathrm{r}}$ of 50045 (Fig. 5). The N-terminal amino acid sequence of the enzyme matches exactly with the predicted sequence starting at residue 39 . Treatment of the enzyme with cyanogen bromide followed by SDS-PAGE and electroblotting (Matsudaira, 1987) produced a peptide 


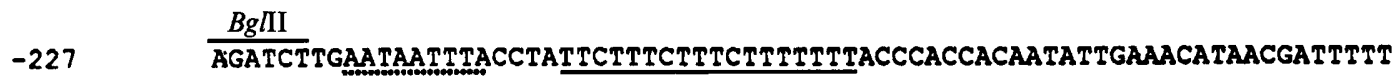
-156 CCAATTTGCGGTCAAATTTACAAGTCCTATTTAATAAAGCTCAATTTCAACAAGTAGCATTTCATTTCAATTAGATTT

-78 TCTTTCCCTTCTTITTTTTTAAATTGTTCTTCATTACATTTGAATCAAACATATCAAAGATTAATACATAATCAGCT

1 ATGCAGTTATCATTTATCTTAACATCATCGgTATTTATATTATTGCTTGAATTTGTTAAAGCCCTGGTTATTTCTAAT $\begin{array}{lllllllllllllllllllllllllllllll}M & Q & L & S & F & I & L & T & S & S & V & F & I & L & L & L & E & F & V & K & A & L & V & I & S & N & 26\end{array}$

79 CCATTTAAACCAAATGGAACTTGAAATCAAGAGAGGAGGCGgaCATAATGTTGCTTGGGATTATGATAATAATGTT $\begin{array}{lllllllllllllllllllllllllll}P & F & K & P & N & G & N & L & K & F & K & R & G & G & G & H & N & V & A & W & D & Y & D & N & N & V & 52\end{array}$

157 ATCAGAGGTGTCAATTTGGGTGGTGGTTTGTCCTTGAACCATATATGACACCATCACTTTTTGAACCATTCCAAAAT $\begin{array}{llllllllllllllllllllllllllll}I & R & G & V & N & L & G & G & W & F & V & L & E & P & Y & M & T & P & S & L & E & E & P & F & O & N & 78\end{array}$

235 GGAAATGATCAGTCTGGAGTTCCAGTTGACGAATATCACTGGACACAAACTTTGGGTAAGGAAGCTGCTCTGAGAATT $\begin{array}{lllllllllllllllllllllllllllll}G & N & D & Q & S & G & V & \text { P } & \text { V } & \text { D } & \text { E } & \text { Y } & \text { H } & \text { W } & \text { T } & Q & \text { T } & \text { L } & G & \text { K } & \text { E } & \text { A } & \text { A } & \text { L } & \text { R } & \text { I } & 104\end{array}$

313 TTGCAAAAACATTGGAGTACTTGGATCACTGAACAAGACTTTAAACAAATTAGTAATTTGGGATTGAACTTTGTTCGT $\begin{array}{llllllllllllllllllllllllllll}\text { L } & Q & K & \text { H } & \text { W } & \text { S } & \text { T } & \text { W } & \text { I } & \text { T } & \text { E } & \text { Q } & \text { D } & \text { F } & \text { K } & \text { Q } & \text { I } & \text { S } & \text { N } & \text { L } & \text { G } & \text { L } & \text { N } & \text { F } & \text { V } & \text { R } & 130\end{array}$

391 ATTCCTATTGGTATTGGGCTTTCCAATTGTTGGATAATGATCCATACGTCCAAGGTCAAGTTCAGTATTTGGAAAAG $\begin{array}{lllllllllllllllllllllllllll}I & P & I & G & Y & \text { W } & A & F & Q & \text { L } & \text { L } & \text { D } & \text { N } & \text { D } & \text { P } & \text { Y } & \text { V } & \text { Q } & \text { G } & \text { Q } & \text { V } & \text { Q } & \text { Y } & \text { L } & \text { E } & \text { K } & 156\end{array}$

469 GCTTTGGGCTGGGCCAGAAAGAATAATATCAGAGTTTGGATTGATTTGCACGGTGCACCAGGCTCTCAAAATGGGTTT $\begin{array}{lllllllllllllllllllllllllllll}A & L & G & W & A & R & K & N & N & I & R & V & W & I & D & I & H & G & A & P & G & S & Q & N & G & F & 182\end{array}$

547 GACAACTCCGGTTTAAGAGATAGCTACAATTTCCAAAACGGTGATAACACCCAAGTTACTTTGAATGTATTGAATACT $\begin{array}{lllllllllllllllllllllllllll}D & N & S & G & L & R & D & S & Y & N & F & Q & N & G & D & N & T & Q & V & T & \text { L } & N & V & \text { L } & \text { N } & \text { T } & 208\end{array}$

625 ATTTTCAAAAAGTATGGTGGCAACGAATACTCTGACGTTGTTATTGGTATTGAATTGCTTAATGAACCATTGGGTCCA $\begin{array}{llllllllllllllllllllllllllll}I & F & K & K & Y & G & G & N & E & Y & S & D & V & V & I & G & I & E & I & I & N & E & P & \text { L } & G & P & 234\end{array}$

703 GTTTTGAATATGGATAATTGAAACAATTTTCTTGGATGgTTACAACTCTCTTAGACAAACTGGaTCAGTCACCCCA $\begin{array}{lllllllllllllllllllllllllll}V & L & N & M & D & K & L & K & Q & F & F & L & D & G & Y & N & S & L & R & Q & T & G & S & V & T & P & 260\end{array}$

781 GTTATCATTCACGATGCTTTCCAAGTCTTTGGCTATTGGAATAACTTTTTGACTGTTGCTGAAGGTCAATGGATGTT $\begin{array}{lllllllllllllllllllllllllllll}\text { V } & I & I & H & D & A & F & Q & \text { V } & \text { F } & G & \text { Y } & W & \text { N } & \text { N } & \text { F } & \text { L } & \text { T } & \text { V } & \text { A } & \text { E } & G & Q & \text { W } & \text { N } & \text { V } & & 286\end{array}$

859 GTTGTTGACCATCATCATTACCAAGTGTTTTCCGGTGGTGAATTATCTCGTAACATTAACGACCACATTTCAGTTGCT $\begin{array}{llllllllllllllllllllllllllll}\text { V } & \text { V } & \text { D } & \text { H } & \text { H } & \text { H } & \text { Y } & \text { Q } & \text { V } & \text { F } & \text { S } & \text { G } & \text { G } & \text { E } & \text { L } & \text { S } & \text { R } & \text { N } & \text { I } & \text { N } & \text { D } & \text { H } & \text { I } & \text { S } & \text { V } & \text { A } & 312\end{array}$

937 TGTAACTGGGGTTGGGATGCTAAAAAGGAATCCCATTGGAACGTCGCTGGTGAATGGTCTGCTGCTTTGACAGATTGT $\begin{array}{lllllllllllllllllllllllllllll}\text { C } & \text { N } & \text { W } & G & \text { W } & D & A & K & K & E & S & \text { H } & \text { W } & \text { N } & \text { V } & \text { A } & G & E & \text { W } & \text { S } & \text { A } & \text { A } & \text { L } & \text { T } & \text { D } & \text { C } & 338\end{array}$

1015 GCTAAATGGTTGATGGTGTCAACAGAGGAGCACGTTATGAGGGTGCTTACGATAATGCTCCATACATTGGATCCTGT

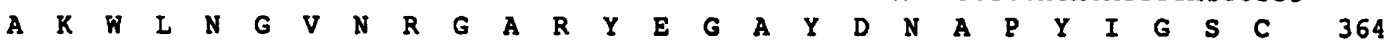

1093 CAACCATTGTTGGATATTTCCCAATGGTCTGATGAACACAAAACCGACACAAGAAGATACATTGAGGCTCAATTGGAT $\begin{array}{llllllllllllllllllllllllllll}Q & P & I & I & D & I & S & Q & W & S & D & E & \text { H } & K & \text { T } & \text { D } & \text { T } & R & R & \text { Y } & \text { I } & \text { E } & \text { A } & Q & \text { L } & \text { D } & 390\end{array}$

1171 GCTTTTGAATACACTGGAGGCTGGGTCTTCTGGAGTTGGAAGACTGAAAATGCCCCTGAATGGAGTTTCCAAACCTTG $\begin{array}{lllllllllllllllllllllllllll}\text { A } & F & E & Y & \text { T } & G & G & W & V & F & W & S & W & K & T & E & N & A & P & E & W & S & F & O & T & L & 416\end{array}$

1249 ACTTACAATGGTCTTITCCCACAACCAGTTACTGATAGACAATTCCCAAACCAATGTGGCTTTCACTGATTAAGGCGT $\begin{array}{llllllllllllllllllllllll}T & Y & N & G & L & F & P & Q & P & V & T & D & R & Q & F & P & N & Q & C & G & F & H & \text { * }\end{array}$

1327 CTTGATTCTACATGAGCAATAATAATTTTAAAAAAAAAATITAAAAAAAAATTCTTCTCAAAATAGGCTTTTACAC 1405 GTTGTTTTCTTTTAAAGATTAGTTATAGAGTTTCAACATTATTTGTGATGTTGAAAATAATTATGAAAAAGTCTCATT 
which yielded 25 residues in the amino acid sequencer. This sequence matched the deduced sequence starting at residue 239 and after Met $_{238}$. The gene does not contain any introns. A codon bias index (Bennetzen \& Hall, 1982) for the gene was calculated giving a value of 0.44 , which is consistent with a moderate level of expression and is similar to that calculated for the exoglucanase gene (EXGI) of S. cerevisiae (Vasquez de Aldana et al., 1991). There are no potential $N$-linked glycosylation sites (Asn-X-Ser $/{ }_{\text {Thr }}$ ) and this is consistent with the carbohydrate analyses of the enzyme in the present and previous study (Luna-Arias et al., 1991). In contrast, the exoglucanase of $S$. cerevisiae has two potential sites and both may be glycosylated (Ramirez et al., 1989). The leader peptide (residues 1-38) contains a block of hydrophobic residues typical of signal sequences (residues 5-16) with potential sites for the signal peptidase after residue 21 or 25 (von Heijne, 1986). The remainder of the leader sequence is probably removed by a Kex2-like endoproteinase because a required recognition sequence (KR) immediately precedes $G_{39}$, the $\mathrm{N}$-terminal residue of the mature enzyme. The predicted size of the mature secreted exoglucanase is therefore 400 residues, with $M_{\mathrm{r}} 45682$. The $\mathrm{Kex} 2$ endoproteinase is located in a late compartment of the Golgi network (Fuller et al., 1989), thus removing the leader peptide just prior to secretion. Other secreted enzymes of yeasts and fungi which undergo similar processing by a Kex2-like endoproteinase include the exoglucanase of $S$. cerevisiae (Vasquez de Aldana et al., 1991), glucoamylase (Innis et al., 1985; Itoh et al., 1987), an aspartic proteinase (Hube et al., 1991; R. J. Wright, personal communication) and an alkaline proteinase (Matoba et al., 1988). Kex2 endoproteinase processing of secreted proteinases could ensure that they are inactive prior to secretion; however it is not clear why this is necessary for the exoglucanase. Analysis of the upstream sequences of the exoglucanase ORF identified several sequences similar to the consensus sequences of elements important for transcription. At positions $-219,-129$ and -60 there are putative TATA boxes, at positions $-158,-147$ and -118 , putative CAAT boxes (Benoist et al., 1980) and at positions -206 and -81 , CT blocks (Dobson et al., 1982).

Comparison of the $C$. albicans and $S$. cerevisiae exoglucanase sequences show they share a $57.8 \%$ identity at the amino acid level and $85 \%$ if conservative substitutions are included (Fig. 6). No other sequences in the EMBL or Genbank databases showed significant homology to either of these sequences.

\section{Expression of exoglucanase}

Glucanases have been implicated in the loosening or modification of the cell wall for expansion during growth. The expression of exoglucanase would therefore be expected to closely follow growth. A single transcript of $2.5 \mathrm{~kb}$ was detected by Northern blot analysis (Fig. $7 a$ ). The amount of exoglucanase mRNA per cell was maximal during the early rapid growth phase $\left(\mathrm{OD}_{600}=1\right.$ to 4) and it then gradually declined as the growth slowed. At $\mathrm{OD}_{600}=32$ the level was at least 100 -fold lower than that of the early-growth-phase cells. Secretion of the exoglucanase was measured by Western blot analyses of the growth medium (Fig. $7 b$ ). This showed that secreted exoglucanase is stable and accumulated throughout growth and into the stationary phase. Although the exoglucanase mRNA is maximally expressed at early exponential phase, the enzyme was not detected in the growth medium at this stage because of the low cell density and the sensitivity of the antiserum.

\section{Discussion}

In the present study an exoglucanase was purified from the growth medium of $C$. albicans ATCC 10261. This represents a more convenient and workable source of the enzyme than cell extracts which contain the enzyme derived from the wall and the intracellular pools. As judged by mobility in SDS-PAGE, N-terminal amino acid sequence ( 35 identical residues) and the absence of $N$-linked oligosaccharides the enzyme purified in the present study is the same as that obtained from the growth medium of $C$. albicans strains 3153a and 1001 (Luna-Arias et al., 1991). It is also probable that the heterodimeric preparations of exoglucanase purified from cell extracts of $C$. albicans strain 1001 (Molina $e t$ al., 1989) contains the same catalytic unit of $M_{\mathrm{r}}$ $40000 \pm 2000$. The enzyme derived from the culture medium and cell extracts are similar with respect to specific activities (allowing for the $M_{\mathrm{r}} 60000$ protein in cell-extract-derived preparation), the ratio of activities towards laminaran and $p$-nitrophenyl- $\beta$-glucoside, and the $K_{\mathrm{m}}$ for laminaran $(H$. Stubbs \& P. Sullivan, unpublished results). The strong hydrophobic binding site exploited in the purification devised in the present

Fig. 5. Nucleotide sequence of the $2.3 \mathrm{~kb} B g I \mathrm{II}-X b a \mathrm{I}$ fragment containing the exoglucanase gene. Numbers with respect to the first nucleotide of the initiation codon are on the left while the deduced amino acid sequence is numbered on the right. Putative upstream

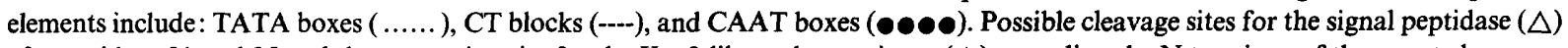
after residues 21 and 25 and the processing site for the Kex2-like endoproteinase $(\boldsymbol{\Delta})$ preceding the $\mathbf{N}$ terminus of the secreted enzyme are indicated. 


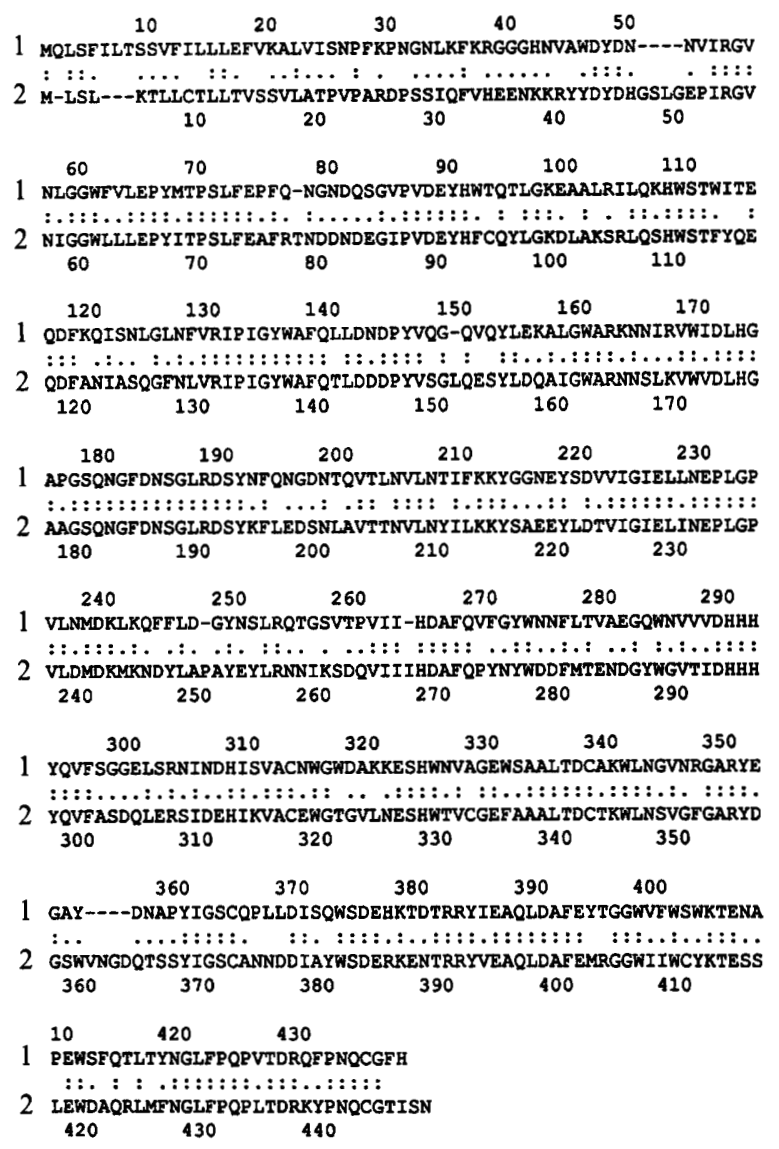

Fig. 6. Alignment of the deduced amino acid sequences of the exoglucanases of $C$. albicans (1) and $S$. cerevisiae EXG1 (2). The sequences were aligned using the program ALIGN. Two dots indicate identical residues, one dot represents similar residues.

study may account for the association of the enzyme with the $M_{\mathrm{r}} 60000$ protein in the cell extract preparations. If the catalytic units of the exoglucanases from cell extracts and the growth medium are the same, the physiological significance of the association with the $M_{\mathrm{r}} 60000$ subunit could be of interest. The basis for the hydrophobic domain is not apparent in the deduced amino acid sequence, but this and other structural features should become apparent now that crystals of the enzyme have yielded a native data set to $1.9 \AA$ (Cutfield et al., 1992).

Deduced sequences within the ORF matched exactly with the N-terminal and an internal sequence of the purified enzyme. Consistent with the protein analysis there are no sites within the sequence for $N$-glycosylation. In other respects, the $C$. albicans gene has high homology with the two $\beta$ - $(1,3)$-exoglucanases genes $E X G 1$ (Vasquez de Aldana et al., 1991) and the sporulation-specific $S S G$ (F. del Rey, personal communication) cloned from $S$. cerevisiae. EXG1 and the $C$. albicans genes encode similar ORFs (448 and 438 amino acid residues respectively); there are Kex 2 processing sites at the amino termini of the mature enzymes and the sequence identity

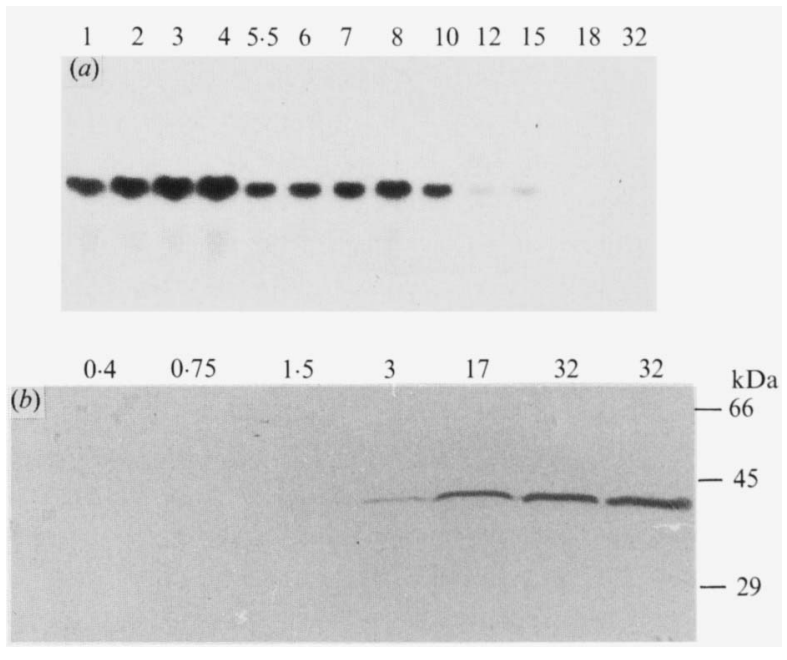

Fig. 7. Expression of the exoglucanase gene. (a) A YPD culture was grown at $30^{\circ} \mathrm{C}$ and $0.8 \mathrm{ml}$ samples of the culture media were taken at $0,1,2,4,10,24$ and $48 \mathrm{~h}$. Growth at these times $\left(\mathrm{OD}_{600}\right)$ is given above. The samples were analysed on a Western blot using the exoglucanase antiserum (see Methods). (b) Total RNA was prepared from cells of a YPD culture harvested at various stages of growth. The RNA samples were analysed on a Northern blot using the $2.5 \mathrm{~kb} \mathrm{BglII}-P s t$ fragment of pXG29 as a probe (see Methods). Each lane contains approximately the same amount of total RNA and the stringency conditions were $65^{\circ} \mathrm{C}$ with $0.1 \times$ SSC, $0.5 \%$ SDS.

( $58 \%$ overall) is apparent throughout the sequences. It is not possible, however, to reconcile the apparent $M_{\mathrm{r}}$ values of the two enzymes obtained by SDS-PAGE. The deglycosylated product of EXG1 migrates as expected for the polypeptide of 408 residues (Ramirez et al., 1989) but the C. albicans enzyme of 400 residues migrates with an apparent $M_{\mathrm{r}}$ of 42000 (this study) or 38000 (LunaArias et al., 1991).

As discussed above, several exoglucanases are produced by $S$. cerevisiae, but only one exoglucanase gene was detected by Southern analysis of genomic DNA from $C$. albicans. A $B g I I I$ RFLP between chromosomal homologues was however detected at this locus. This is precedented by the report of a EcoRI RFLP at the URA3 locus of several C. albicans strains (Kelly et al., 1987).

CT blocks upstream of genes have been associated with constitutively or highly expressed genes in $S$. cerevisiae (Dobson et al., 1982). These are present in both the $S$. cerevisiae and $C$. albicans exoglucanase genes and may be important for expression. A $1.7 \mathrm{~kb}$ mRNA transcript was reported for $E X G 1$ of $S$. cerevisiae and this is consistent with the putative transcription elements associated with the gene (Vasquez de Aldana et al., 1991). The mRNA transcript of the $C$. albicans gene, however, was $2.5 \mathrm{~kb}$ meaning that either transcription initiation and/or termination occurs further away from the ORF or that the transcript contains a very long poly(A) tail. The exoglucanase transcript was expressed maximally during growth and this confirms earlier 
studies with S. cerevisiae (del Rey et al., 1979). The rate of accumulation of exoglucanase in the growth medium was not proportional to the level of the mRNA transcript. The accumulation of exoglucanase in the growth medium, however, may be delayed because of the rates of translation, secretion and release of the enzyme from the cell wall. Expression was at a moderate level as judged by the Northern and Western blots and this was consistent with the codon bias index.

Identification of sequences that constitute the catalytic and binding site is not possible at this stage. There is no overall sequence homology with other glycanase sequences in the data bases. It is noteworthy however that the sequences LEP (residues 64-66) and NEP (residues 229-231) are highly conserved in many $1,4-\beta$ glucanases and that the NEP sequence is essential for catalytic activity (Baird et al., 1990).

This work was supported by grants from the Health Research Council of New Zealand and the University of Otago. We are grateful to Ms. Liz Legerwood for carrying out some of the protein sequencing for this work.

\section{References}

Ausubel, F. M., Brent, R., Kingston, R. E., Moore, D. D., Smith, J. A., Seidman, J. G. \& Struhl, K. (1987). Current Protocols in Molecular Biology. New York: John Wiley \& Sons.

BaIRD, S. D., HefFord, M. A., Johnson, D. A., Sung, W. L., YAGUChI, M. \& Seligy, V. L. (1990). The GLU residue in the conserved ASN-GLU-PRO sequence of two highly divergent endo$\beta$-1,4-glucanases is essential for enzymatic activity. Biochemical and Biophysical Research Communications 169, 1035-1039.

Bankier, A. T., Weston, K. M. \& Barrell, B. G. (1987). Random cloning and sequencing by the M13/dideoxynucleotide chain termination method. Methods in Enzymology 155, 51-93.

Bennetzen, J. L. \& Hall, B. D. (1982). Codon selection in yeast. Journal of Biological Chemistry 257, 3026-3031.

Benoist, C., O'Hare, K., Breathnach, R. \& Chambon, P. (1980). The ovalbumin gene - sequence of putative control regions. Nucleic Acids Research 8, 127-142.

Brown, T. A. (1991). Molecular Biology Labfax. Oxford: Bios Scientific Publishers \& Blackwell Scientific Publications.

BRUSS, M. L. \& BLACK, A. L. (1978). Enzymatic microdetermination of glycogen. Analytical Biochemistry 84, 309-312.

Cenamor, R., Molina, M., Galdona, J., Sanchez, M. \& Nombela, C. (1987). Production and secretion of Saccharomyces cerevisiae $\beta$ glucanases: differences between protoplast and periplasmic enzymes. Journal of General Microbiology 133, 619-628.

CRYER, D. R., ECCLESHALl, R. \& MARMUR, J. (1975). Isolation of yeast DNA. Methods in Cell Biology 12, 39-44.

Cutfield, S., Brooke, G., Sullivan, P. \& Cutfield, J. (1992). Crystallization of the exo(1,3)- $\beta$-glucanase from Candida albicans. Journal of Molecular Biology 225, 217-218.

DAvis, B. J. (1964). Disc electrophoresis II: Method and application to human serum proteins. Annals of the New York Academy of Sciences 121, 404427.

Dobson, M. J., Tuite, M. F., Roberts, N. A., Kingsman, A. J. \& KingSMan, S. M. (1982). Conservation of high efficiency promoter sequences in Saccharomyces cerevisiae. Nucleic Acids Research 10, 2625-2637.

DUNN, S. D. (1986). Effects of the modification of transfer buffer composition and the renaturation of proteins in gels on the recognition of proteins on western blots by monoclonal antibodies. Analytical Biochemistry 157, 144-153.
Feinberg, A. P. \& Vogelstein, B. (1984). Addendum: A technique for radiolabelling DNA restriction endonuclease fragments to high specific activity. Analytical Biochemistry 137, 266-267.

FLeET, G. H. (1991). Cell walls. In The Yeasts, 2nd edition, Vol. 4, pp. 199-277. Edited by A. H. Rose \& J. S. Harrison. London: Academic Press.

Fuller, R. S., BRAKe, A. J. \& ThORNER, J. (1989). Intracellular targeting and structural conservation of a prohormone-processing endoprotease. Science 246, 482-485.

GABRIEL, O. \& WANG, S. (1969). Determination of enzymatic activity in polyacrylamide gels. Analytical Biochemistry 27, 545-554.

GROSSBERGER, D. (1987). Minipreps of DNA from bacteriophage lambda. Nucleic Acids Research 15, 6737.

voN HeisNe, G. (1986). A new method for predicting signal sequence cleavage sites. Nucleic Acids Research 14, 4683-4690.

HIEN, N. H. \& FleEt, G. H. (1983). Separation and characterisation of six $(1,3)-\beta$-glucanases from Saccharomyces cerevisiae. Journal of Bacteriology 156, 1204-1213.

Hube, B., Turver, C. J., Odds, F. C., Eiffert, H., Boulnois, G. J., KOCHEL, H. \& RUCHel, R. (1991). Sequence of the Candida albicans gene encoding the secretory aspartate proteinase. Journal of Medical and Veterinary Mycology 29, 1-4.

Innis, M. A., Holland, M. J., McCabe, P. C., Cole, G. E., Wittman, V., Tal, R., Watt, K. W. K., Gelfand, D. H., Holland, J. P. \& MEADE, J. H. (1985). Expression, glycosylation, and secretion of an Aspergillus glucoamylase by Saccharomyces cerevisiae. Science $\mathbf{2 2 8 ,}$ 21-25.

IтoH, T., Ohtsuki, I., Yamashita, I. \& FukUi, S. (1987). Nucleotide sequence of the glucoamylase gene GLU1 in the yeast Saccharomycopsis fibuligera. Journal of Bacteriology 169, 4171-4176.

Kelly, R., Miller, S. M., KuRTZ, M. B. \& KIrSCH, D. R. (1987). Directed mutagenesis in Candida albicans: one-step gene disruption to isolate URA3 mutants. Molecular and Cellular Biology 7, 199-207.

LAEMMLI, U. K. \& FAVRE, M. (1973). Maturation of the head of bacteriophage T4. Journal of Molecular Biology 80, 575-599.

Luna-Arias, J. P., Andaluz, E., Ridruejo, J. C., Olivero, I. \& LARRIBA, G. (1991). The major exoglucanase from Candida albicans: a non-glycosylated secretory monomer related to its counterpart from Saccharomyces cerevisiae. Yeast 7, 833-841.

Matoba, S., Fukayama, J., Wing, R. A. \& OgRydziak, D. M. (1988). Intracellular precursors and secretion of alkaline extracellular protease of Yarrowia lipolytica. Molecular and Cellular Biology 8, $4904-4916$.

MatsudaiRa, P. (1987) Sequence from picomole quantities of proteins electroblotted onto polyvinylidene difluoride membranes. Journal of Biological Chemistry 262, 10035-10038.

Molina, M., CenamoR, R. \& Nombela, C. (1987). Exo-1,3- $\beta$-glucanase activity in Candida albicans: effect of the yeast to mycelium transition. Journal of General Microbiology 133, 609-617.

Molina, M., Cenamor, R., Sanchez, M. \& Nombela, C. (1989). Purification and some properties of Candida albicans exo-1,3- $\beta$ glucanase. Journal of General Microbiology 135, 309-314.

Nombela, C., Molina, M., Cenamor, R. \& Sanchez, M. (1988). Yeast $\beta$-glucanases: a complex system of secreted enzymes. Microbiological Sciences 5, 328-332.

Pearson, W. R. \& Lipman, D. J. (1988). Improved tools for biological sequence comparisons. Proceedings of the National Academy of Sciences of the United States of America 85, 2444-2448.

Peterson, G. L. (1977). A simplification of the protein assay method of Lowry et al. which is more generally applicable. Analytical Biochemistry 87, 386-396.

Ram, S. P., Hynes, K. H., Romana, L. K., ShePherd, M. G. \& Sullivan, P.A. (1988). The $\beta$-glucanases and $\beta$-glucosidase of Candida albicans. Biochemistry (Life Science Advances) 7, 379-383.

Ramirez, M., Hernandez, L. M. \& LarRiba, G. (1989). A similar protein portion for two exoglucanases secreted by Saccharomyces cerevisiae. Archives of Microbiology 151, 391-398.

Ramirez, M., Munoz, M. D., Basco, R. D., Gimenez-Gallego, G., HeRnandez, L. M. \& LaRRIBA, G. (1990). Two glycosylation patterns for a single protein (exoglucanase) in Saccharomyces cerevisiae. FEMS Microbiology Letters 71, 43-48.

DEL REY, F., GARCIA-ACHA, I. \& Nombela, C. (1979). The regulation of 
$\beta$-glucanase synthesis in fungi and yeast. Journal of General Microbiology 110, 83-89.

del Rey, F., Villa, T. G., Santos, T., Garcia-Acha, I. \& Nombela, C. (1982). Purification and partial characterisation of a new, sporulation specific, exo- $\beta$-glucanase from Saccharomyces cerevisiae. Biochemical and Biophysical Research Communications 105, 1347-1353.

Sambrook, J., Fritsch, E. F. \& Maniatis, T. (1989). Molecular Cloning: a Laboratory Manual, 2nd edn. Cold Spring Harbor, NY: Cold Spring HarborLaboratory.

Schmitt, M. E., Brown, T. A. \& Trumpower, B. L. (1990). A rapid and simple method for preparation of RNA from Saccharomyces cerevisiae. Nucleic Acids Research 18, 3091-3092.

Staden, R. \& MCLACHLan, A. D. (1982). Codon preference and its use in identifying protein coding regions in long DNA sequences. Nucleic Acids Research 10, 141-174.

Stockwell, P. A. (1985). VTUTin: A full screen gel management editor. Computer Applications in the Biosciences 1, 253-259.

Stockwell, P. A. \& Petersen, G. B. (1987). homed: A homologous sequence editor. Computer Applications in the Biosciences 3, 37-43.

Trimble, R. B. \& MaleY, F. (1984). Optimising hydrolysis of $N$-linked high mannose oligosaccharides by endo- $\beta$ - $N$-acetylglucosaminidase H. Analytical Biochemistry 141, 515-522.

Vasquez de Aldana, C. R., Correa, J., San Segundo, P., Bueno, A., NebredA, A. R., MENDEZ, E. \& Del ReY, F. (1991). Nucleotide sequence of the exo-1,3- $\beta$-glucanase-encoding gene, EXGl, of the yeast Saccharomyces cerevisiae. Gene 97, 173-182. 